\title{
Amelioration of Diabetic Dyslipidemia by GTF - 231 (Gymnemic acid, Trigonelline and Ferulic acid- 2:3:1), a phytochemical preparation Studied in High Fat Diet Fed-Low Dose STZ Induced Experimental Type 2
} Diabetes in Rats

\author{
V. Roshana Devi, C. Sharmila and S. Subramanian*
}

Department of Biochemistry, University of Madras, Guindy Campus, Chennai 600 025, India

\begin{abstract}
:
Background: Persistent hyperglycemia in diabetes is associated with profound changes in lipid and lipoprotein abnormalities which result in particle distribution within lipoprotein classes. Recently, we have reported the antidiabetic properties of GTF-231 (Gymnemic acid, Trigonelline and Ferulic acid- 2:3:1) a phytochemical preparation in experimental type 2 diabetic rats. The present study was aimed to evaluate the effect of GTF-231 on the regulation of lipid homeostasis in T2DM induced rats.

Materials and methods: High fat diet fed-low dose STZ induced experimental type 2 diabetes was used as the animal model. GTF at a concentration of $300 \mathrm{mg} / \mathrm{kg}$. b.w./rat $/$ day was orally administered for 30 days to experimental type 2 diabetic rats. The alterations in the levels of lipid profile in plasma, hepatic and renal tissues were studied. The activities of HMG CoA reductase was assayed in liver and kidney tissues of control and experimental groups of rats. The levels of lipid metabolizing enzymes such as lipoprotein lipase and lecithin cholesterol acyltransferase in the plasma and hepatic tissues were assayed.

Results: Oral administration of GTF-231significantly normalized the altered levels of lipid profile in plasma, hepatic and renal tissues. Likewise, the decreased levels of HDL-c and increased levels of LDL-c and VLDL-c in plasma of diabetic rats were normalized upon treatment with GTF. Additionally,GTF-231 treatment significantly decreased the activity HMG-CoA reductase in the liver and kidney tissues. Decreased activities of lipid metabolizing enzymes such as lipoprotein lipase and lecithin cholesterol acyltransferase in the plasma and hepatic tissues were normalized upon oral treatment with GTF-231.

Conclusion: The data obtained are claimed to display synergistic, efficacious and agonistic/antagonistic actions of GTF-231 and the mixture of species in the phytochemical preparation shows better therapeutic effects at a relatively less concentration than either species on its own and the ameliorative potential of GTF-231 in diabetic dyslipidemia was comparable with metformin (200 mg/kg.b.w.).
\end{abstract}

Keywords: Type 2 diabetes; High fat diet-low dose STZ; GTF-231; Lipid profile; Lipoproteins; Lipoprotein lipase

*Corresponding author: Dr. S. Subramanian, Department of Biochemistry, University of Madras, Guindy campus, Chennai - 600 025, Tamilnadu, India, Tel: +91-44-22202732; E-mail: subbus2020@yahoo.co.in

Citation: Subramanian,S.S., et al. Amelioration of Diabetic Dyslipidemia by GTF - 231 (Gymnemic acid, Trigonelline and Ferulic acid- 2:3:1), a phytochemical preparation Studied in High Fat Diet Fed-Low Dose STZ Induced Experimental Type 2 Diabetes in Rats. (2018) J diab Obes 5(1): 1- 9. 
Citation: Subramanian,S.S., et al. Amelioration of Diabetic Dyslipidemia by GTF - 231 (Gymnemic acid, Trigonelline and Ferulic acid- 2:3:1), a phytochemical preparation Studied in High Fat Diet Fed-Low Dose STZ Induced Experimental Type 2 Diabetes in Rats. (2018) J diab Obes 5(1): 1- 9.

\section{Introduction}

Both hyperglycemia and hyperlipidemia share most of the common clinical features contributing to the development of microvascular as well as macrovascular complications of diabetes mellitus[1]. Diabetic dyslipidemia increases the risk of myocardial and cerebral infarctions which are the major causes of morbidity and mortality worldwide comparable to cancer in developed countries[2]. The incidence of coronary heart diseases remains set to rise vividly as more populated parts of the Asia become increasingly wealthy and adopt an atherosclerotic prone lifestyle. The prevalence of lipid abnormalities in patients with $\mathrm{T} 2 \mathrm{DM}$ is twice as in the non-diabetic individuals because of the interaction among obesity, insulin resistance and chronic hyperglycemia. It is more complex in T2DM than observed in individuals with type 1 diabetes because LDL-C levels are usually within the physiological range with controlled T1DM[3]. Experimental and clinical studies have demonstrated that the excess low-density lipoprotein cholesterol (LDL-c) deposited in the artery walls is a major risk factor in the initiation and progression of atherosclerosis impasse[4,5]. Elevated levels of LDL-c are also reported in prediabetics, patients with insulin resistance but normal indexes of plasma glucose[6].

So far, Thirteen Nobel Prizes have been awarded to eminent find a more fitting wordwho dedicated major parts of their career to cholesterol research[7]. Though the lipid-lowering drugs such as statins, fibrates and bile acid sequestrants regulate the lipid metabolism by different mechanisms, they often elicit undesirable side effects such as hyperuricemia, diarrhea, nausea, myopathy, gastrointestinal disorders, dry skin and liver dysfunction[8]. Hence, a continuous impetus for the development of more efficacious and safety lipid-lowering drugs capable of modulating HDL-c metabolism and reverse cholesterol transfer (RCT) preferably from natural sources continues.

T2DM accounts for more than $90 \%$ of the diabetic population worldwide and because of its multifactorial and multisystemic nature, a multitherapeutic approach capable of influencing multiple targets concurrently is preferred due to less prone drug-induced toxicity and resistance[9]. However, formulation and synthesis of multicomponent allopathic drugs are limited due to their variation in the composition of individual components, mechanism of action, stability, bioavailability, multidrug resistance and economic unfeasibility. Conversely, a mixture comprising components preferably from plant origin with specified pharmacological properties are often favored because of their availability, accessibility, affordability, efficacy, stability and safety. They are claimed to display synergistic, efficacious and agonistic/antagonistic actions and the mixture of species in them shows better therapeutic effects at a relatively less concentration than either species on its own.

Recently, we have reported the antidiabetic properties of GTF-231 (Gymnemic acid, Trigonelline and Ferulic acid2:3:1) in high fat diet fed- low dose STZ induced experimental type 2 diabetes in rats[10]. Several reports are available in the literature pertaining to the pharmacological properties of Gymnemic acid[11], Trigonelline[12] and Ferulic acid[13]. However, we found that GTF-231 has shown a significant antidiabetic effect at a relatively less concentration than the individual phytochemicals which were used in the reported studies[14].
Building on our previous research, the purpose of this experimental study was to traverse the ameliorative properties of diabetic dyslipidemia by GTF-231 in HFD fed - low dose STZ induced experimental type 2 diabetic rats.

\section{Materials and Methods}

\section{Chemicals}

Gymnemic acid, Trigonelline, Ferulic acid and Streptozotocin were procured from Sigma-Aldrich, stored at $2-4^{\circ} \mathrm{C}$ and protected from light. All other chemicals used were purchased from standard commercial suppliers and were of analytical grade quality.

\section{Maintenance of experimental animals}

Male albino rats of Wistar strain weighing approximately $160-180 \mathrm{~g}$, were procured from Tamil Nadu Veterinary and Animal Sciences University (TANUVAS), Chennai. The rats were housed in spacious polypropylene cages lined with husk. Experimental rats were maintained under the controlled environment at $22 \pm 3^{\circ} \mathrm{C}$ with relative humidity $(50 \pm 10 \%)$ and automatically controlled $12 \mathrm{~h}$ light and dark cycle. Animals were acclimatized to standard husbandry conditions for one week to eliminate the effect of stress prior to instigation of the experiments. The rats were fed with commercial pellet rat chow (Hindustan Lever Ltd., Bangalore, India) and had free access to water ad libitum. The experiments were designed and conducted in strict accordance with the current ethical norms approved by Ministry of Social justices and Empowerment, Government of India and Institutional Animal Ethical Committee guidelines approval (IAEC No. 03/01/2014).

\section{High fat diet fed - single low dose streptozotocin induced type 2 diabetes}

The rats were allocated into two dietary regimens by feeding either normal pellet diet (NPD) or high fat diet (HFD) for 2 weeks of dietary manipulation. The composition of HFD is powdered NPD - $365 \mathrm{~g} / \mathrm{kg}$, lard $-310 \mathrm{~g} / \mathrm{kg}$, casein $-250 \mathrm{~g} /$ $\mathrm{kg}$, cholesterol $-10 \mathrm{~g} / \mathrm{kg}$, vitamin and mineral mix $-60 \mathrm{~g} / \mathrm{kg}$, DL-methionine $-3 \mathrm{~g} / \mathrm{kg}$, yeast powder $-1 \mathrm{~g} / \mathrm{kg}, \mathrm{NaCl}-1 \mathrm{~g} /$ $\mathrm{kg}[15,16]$. After 2 weeks of HFD feeding to induce insulin resistance, Group II, Group III and Group IV rats were intraperitoneally injected with a single dose of STZ (35 mg/kg b.w./), while the Group I rats fed with NPD were injected with $0.5 \mathrm{ml}$ of freshly prepared cold citrate buffer $(\mathrm{pH} 4.5)$ in a same volume intraperitoneally. After one week of STZ injections, rats with fasting blood glucose levels $\geq 250 \mathrm{mg} / \mathrm{dl}$ were considered diabetic and chosen for the present experiments.

\section{Designing of experimental protocol}

The animals were divided into four groups, comprising a minimum of six animals in each group as follows:

\section{Group $1 \quad-\quad$ Control rats.}

Group 2 - $\quad$ High fat diet fed- a single low dose STZ (i.p. $35 \mathrm{mg} / \mathrm{kg}$ b.w.) induced diabetic rats.

Group $3 \quad-\quad$ Diabetic rats treated with GTF-2:3:1 at a concentration of $300 \mathrm{mg} / \mathrm{kg} \mathrm{b.w} /$ rat/dayin aqueous solution orally for 30 days 
Group $4 \quad-\quad$ Diabetic rats treated with metformin (200 mg/ kg b.w/ /day) in aqueous solution orally for 30 days

At the end of 30th day experimental period, the rats were fasted overnight, anesthetized and sacrificed by cervical decapitation. Blood was collected with and without anticoagulants for plasma and serum separation respectively. Liver and kidney tissues were selectively dissected out, washed in ice-cold saline and homogenized in Tris- $\mathrm{HCl}$ buffer $[\mathrm{pH} 7.4(0.1 \mathrm{M})]$, with a Teflon homogenizer.

\section{Biochemical Studies}

The fasting blood glucose level was determined by glucose oxidase diagnostic enzyme kit (Span Diagnostic Chemicals, India) and glycosylated hemoglobin was estimated by the methodof Nayak and Pattabiraman (1981)[17]. Plasma insulin level was assayed using rat ELISA kit (Linco Research, St Charles, MO, USA). The presence of urine sugar was detected using urine strips (Diastix).

\section{Studies on Lipid Profiles}

Total lipids were extracted from liver and kidney tissues by the method of Folch et al. (1957)[18]. The levels of total cholesterol, triglycerides and free fatty acids in plasma, liver and kidney tissues were estimated[19-21]. Phospholipids were estimated according to the method of Bartlett (1959)[22] by digestion with perchloric acid and the phosphate liberated were estimated by the method of Fiske and Subbarow (1925) [23]. High-density lipoproteins (HDL-c), Very low density lipoprotein (VLDL-c) and low-density lipoproteins (LDL-c) were separated from the plasma according to dual precipitation technique[24,25] and the cholesterol content of the lipoproteins was estimated.

Calculation of Atherogenic Index(AI) and Coronary Risk Index (CRI)

$$
\mathrm{AI}=\frac{\mathrm{LDL}-\mathrm{c}(\mathrm{mg} / \mathrm{dl})}{\mathrm{HDL}-\mathrm{c}(\mathrm{mg} / \mathrm{dl})}
$$

$$
\mathrm{CRI}=\frac{\mathrm{TC}(\mathrm{mg} / \mathrm{dl})}{\mathrm{HDL}-\mathrm{c}(\mathrm{mg} / \mathrm{dl})}^{[27]}
$$

\section{HMG CoA reductase activity}

HMG-CoA reductase activity in the tissue samples was calculated by the ratio of $\mathrm{HMG}-\mathrm{CoA}$ to mevalonate conversion[28].

Assay of Lipoprotein Lipase (LPL) and Lecithin Cholesterol Acyltransferase (LCAT)

The plasma and liver LPL activity were measured by the method of Korn (1955)[29] and Schmidt (1974)[30]. The activity of LCAT in plasma and liver tissue was determined by the method of Hitz et al., (1983)[31].

\section{Statistical analysis}

The results were expressed as mean \pm S.E.M of six rats per group and the statistical significance was evaluated by oneway analysis of variance (ANOVA) using the SPSS (version 16) program followed by Least Significance Difference (LSD). Values were considered statistically significant when $\mathrm{p}<0.05$.

\section{Results}

Table 1 demonstrates the effect of GTF-231 treatment on the levels of fasting blood glucose, glycosylated hemoglobin and plasma insulin. These biochemical indices were significantly elevated in the diabetic group when compared to controls. Diabetic rats orally treated with GTF-231 normalized altered biochemical parameters with efficacy comparable to the metformin group. Urine sugar detected in the diabetic rats was no longer present in the diabetic group treated with GTF-231 as well as metformin group.

Table 1: Effect of GTF-231 on the levels of biochemical parameters in the experimental groups of rats

\begin{tabular}{|l|l|l|l|l|}
\hline Groups & $\begin{array}{l}\text { Fasting Blood } \\
\text { Glucose } \\
(\mathrm{mg} / \mathrm{dl})\end{array}$ & $\begin{array}{l}\text { HbAlc } \\
(\% \text { hemo- } \\
\text { globin })\end{array}$ & $\begin{array}{l}\text { Plasma } \\
\text { Insulin } \\
(\mu \mathrm{U} / \mathrm{ml})\end{array}$ & $\begin{array}{l}\text { Urine } \\
\text { Sugar }\end{array}$ \\
\hline Control & $89.23 \pm 2.07$ & $4.95 \pm 0.18$ & $15.79 \pm 1.07$ & Nil \\
\hline Diabetic & $313.24 \pm 8.29^{\mathrm{a}^{*}}$ & $10.76 \pm 0.41^{\mathrm{a}^{*}}$ & $9.18 \pm 0.24^{\mathrm{a}^{*}}$ & +++ \\
\hline $\begin{array}{l}\text { Diabet- } \\
\text { ic+GTF-231 }\end{array}$ & $107.38 \pm 3.01^{\mathrm{b}^{*}}$ & $5.29 \pm 0.51^{\mathrm{b}^{*}}$ & $13.02 \pm 0.64^{\mathrm{b}^{*}}$ & Nil \\
\hline $\begin{array}{l}\text { Diabetic+ } \\
\text { Metformin }\end{array}$ & $102.71 \pm 4.15^{\mathrm{b}^{*}}$ & $5.16 \pm 0.18^{\mathrm{b}^{*}}$ & $12.43 \pm 0.76^{\mathrm{b}^{*}}$ & Nil \\
\hline
\end{tabular}

Values are given as Mean \pm S.E.M for six rats in each group. One way ANOVA followed by post hoc test LSD. Statistical significance was compared within the groups as follows:

${ }^{\mathrm{a}}$ compared with control group of rats;

${ }^{b}$ compared with diabetic group of rats.

Values are statistically significant at $* \mathrm{p}<0.05$.

Figure 1 represents the effect of GTF-231 on the plasma levels of total cholesterol, triglycerides, phospholipids and free fatty acids in the experimental group. The levels were significantly elevated in the diabetic group and oral treatment of GTF-231 restored the altered lipid profile to levels approaching normal in the diabetic group.

Figure 1: The effect of GTF-231 treatment on the plasma levels of total cholesterol, triglycerides, free fatty acids and phospholipids in the experimental groups of rats.

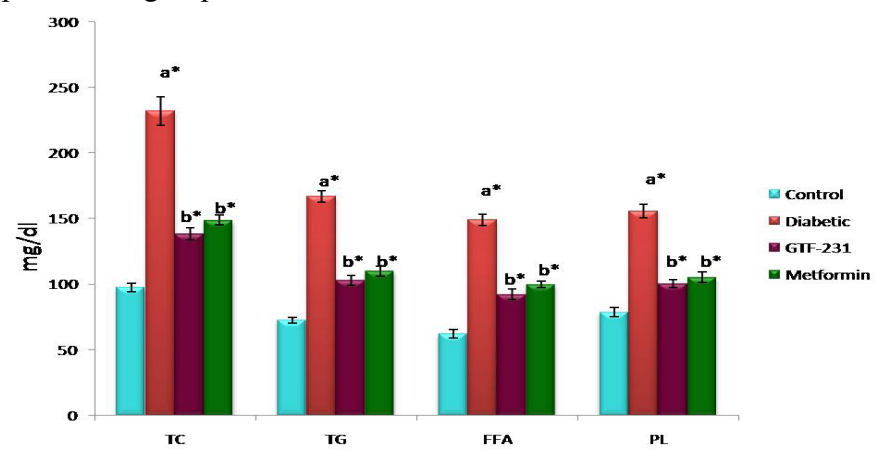

Values are given as Mean \pm S.E.M for six rats in each group. One way ANOVA followed by post hoc test LSD. Statistical significance was compared within the groups as follows:

${ }^{a}$ compared with control group of rats; 
Citation: Subramanian,S.S., et al. Amelioration of Diabetic Dyslipidemia by GTF - 231 (Gymnemic acid, Trigonelline and Ferulic acid- 2:3:1), a phytochemical preparation Studied in High Fat Diet Fed-Low Dose STZ Induced Experimental Type 2 Diabetes in Rats. (2018) J diab Obes 5(1): 1- 9.

${ }^{\mathrm{b}}$ compared with diabetic group of rats.

Values are statistically significant at $* \mathrm{p}<0.05$.

Figure 2 and 3 depict the levels of total cholesterol, triglycerides, phospholipids and free fatty acids in the liver and kidney tissues of control and experimental groups. These levels were significantly increased in the diabetic group, whereas the oral administration of GTF-231 and metformin treated diabetic groups significantly decreased the levels to near normalcy.

Figure 2: The effect of GTF-231 treatment on the liver tissues of total cholesterol, triglycerides, free fatty acids and phospholipids in the experimental groups of rats.

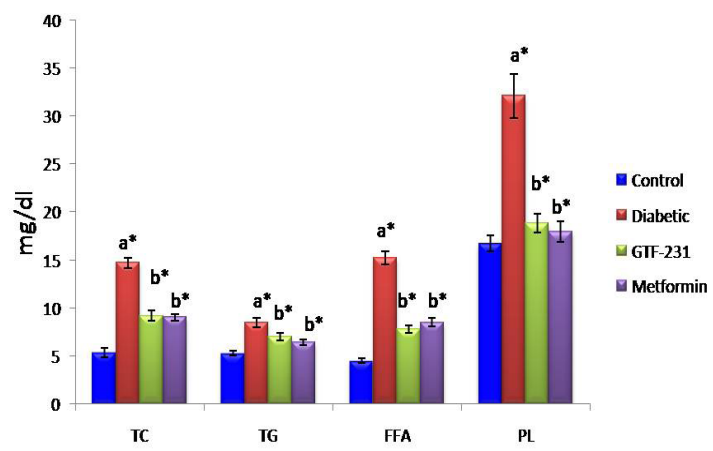

Values are given as Mean \pm S.E.M for six rats in each group. One way ANOVA followed by post hoc test LSD. Statistical significance was compared within the groups as follows:

${ }^{a}$ compared with control group of rats;

${ }^{\mathrm{b}}$ compared with diabetic group of rats.

Values are statistically significant at $* \mathrm{p}<0.05$.

Figure 3: The effect of GTF-231 treatment on the kidney tissues of total cholesterol, triglycerides, free fatty acids and phospholipids in the experimental groups of rats.

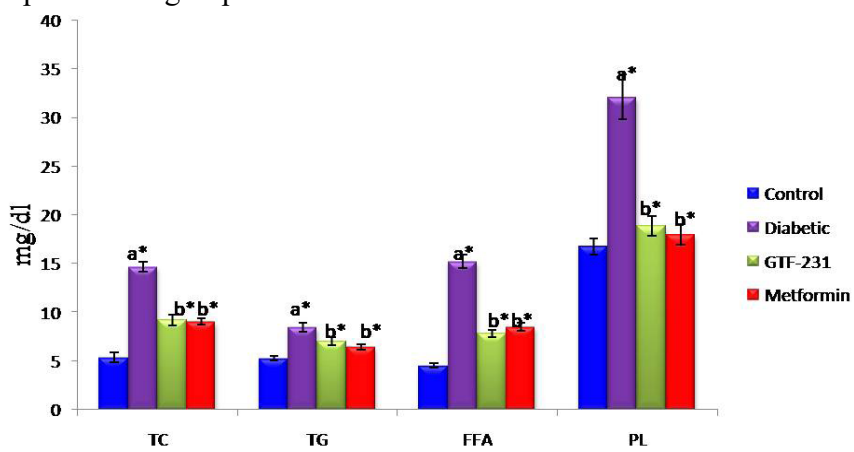

Values are given as Mean \pm S.E.M for six rats in each group. One way ANOVA followed by post hoc test LSD. Statistical significance was compared within the groups as follows:

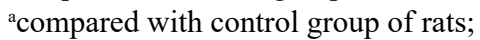

${ }^{\mathrm{b}}$ compared with diabetic group of rats.

Values are statistically significant at $* \mathrm{p}<0.05$.

Table 2 shows the levels of plasma lipoproteins such as HDL, LDL and VLDL in control and experimental groups. Compared to controls, the levels of LDL and VLDL were elevated significantly with a concomitant decline in the levels of HDL in the diabetic group.Oral treatment with GTF effectively decreased the levels of LDL as well as VLDL and improved the HDL levels in the experimental diabetic group.
Table 2: The levels of HDL-Cholesterol, LDL-Cholesterol and VLDL-Cholesterol in plasma of control and experimental groups of rats

\begin{tabular}{|l|c|c|c|}
\hline Groups & \multicolumn{1}{|c|}{ HDL-C } & \multicolumn{1}{c|}{ LDL-C } & VLDL-C \\
\hline Control & $40.89 \pm 1.67$ & $52.12 \pm 4.88$ & $19.51 \pm 1.35$ \\
\hline Diabetic & $11.51 \pm 0.77^{\mathrm{a}^{*}}$ & $180.21 \pm 12.66^{\mathrm{a}^{*}}$ & $46.40 \pm 1.77^{\mathrm{a}^{*}}$ \\
\hline Diabetic + GTF & $35.21 \pm 1.99^{\mathrm{b}^{*}}$ & $60.23 \pm 6.23^{\mathrm{b}^{*}}$ & $22.67 \pm 1.00^{\mathrm{b}^{*}}$ \\
\hline $\begin{array}{l}\text { Diabetic + } \\
\text { Metformin }\end{array}$ & $34.5 \pm 1.78^{\mathrm{b}^{*}}$ & $61.51 \pm 5.81^{\mathrm{b}^{*}}$ & $24.75 \pm 1.63^{\mathrm{b}^{*}}$ \\
\hline
\end{tabular}

Units are expressed as $\mathrm{mg} / \mathrm{dl}$. Values are given as Mean \pm S.E.M for six rats in each group. One way ANOVA followed by post hoc test LSD. Statistical significance was compared within the groups as follows:

${ }^{\text {a }}$ compared with control group of rats;

${ }^{\mathrm{b}}$ compared with diabetic group of rats.

Values are statistically significant at $* \mathrm{p}<0.05$.

Figure 4 illustrates the atherogenic and coronary risk factor index in control and experimental groups. Diabetic rats showed an increased atherogenic and coronary risk factor index compared to the control group. Treatment with GTF-231 and metformin groups reduced the atherogenic and coronary risk factor index. The increased activity of $\mathrm{HMG}-\mathrm{CoA}$ reductase in liver and kidney tissues of diabetic group were significantly decreased upon oral treatment with GTF-231 (Figure 5).

Figure 4: Atherogenic and coronary risk factor index in control and experimental groups of rats

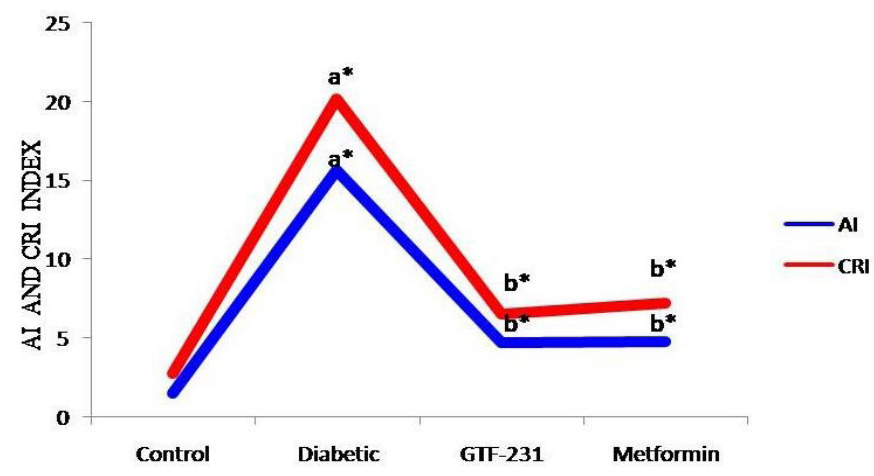

Values are given as Mean \pm S.E.M for six rats in each group. One way ANOVA followed by post hoc test LSD. Statistical significance was compared within the groups as follows: acompared with control group of rats; bcompared with diabetic group of rats. Values are statistically significant at $* \mathrm{p}<0.05$.

Figure 5: The activity of HMG CoA reductase in liver and kidney tissues of control and experimental groups of rats.

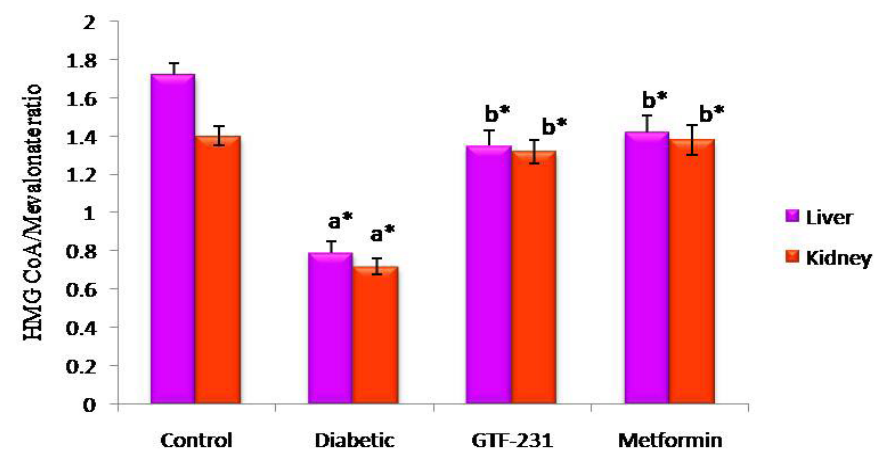

Values are given as Mean \pm S.E.M for six rats in each group. One way ANOVA followed by post hoc test LSD. Statistical significance was 
compared within the groups as follows: acompared with control group of rats; bcompared with diabetic group of rats. Values are statistically significant at $* \mathrm{p}<0.05$.

Table 3 shows the effect of GTF-231 on the activities of lipid metabolizing enzymes such as lipoprotein lipase (LPL) and lecithin cholesterol acyltransferase (LCAT) in plasma and liver tissues. Decreased activity of these lipid metabolizing enzymes was increased upon oral treatment with GTF as well as metformin.

Table 3: The activities of lipid metabolizing enzymes such as lipoprotein lipase and lecithin cholesterol acyltransferase in plasma and liver tissue of control and experimental groups of rats

\begin{tabular}{|c|c|c|c|c|}
\hline \multirow{2}{*}{ Groups } & \multicolumn{2}{|c|}{ LPL } & \multicolumn{2}{c|}{ LCAT } \\
\cline { 2 - 5 } & Plasma & Liver & Plasma & Liver \\
\hline Control & $7.12 \pm 0.51$ & $11.28 \pm 1.51$ & $70.12 \pm 4.51$ & $15.58 \pm 1.61$ \\
\hline \multirow{2}{*}{ Diabetic } & $5.01 \pm$ & $18.01 \pm$ & $55.62 \pm$ & $9.01 \pm$ \\
& $0.38^{\mathrm{a}^{*}}$ & $1.95^{\mathrm{a}^{*}}$ & $3.38^{\mathrm{a}}$ & $1.28^{\mathrm{a}^{*}}$ \\
\hline Diabetic + & $6.56 \pm$ & $12.98 \pm$ & $65.26 \pm$ & $12.56 \pm$ \\
GTF & $0.41^{\mathrm{b}^{*}}$ & $1.48^{\mathrm{b}^{*}}$ & $4.12^{\mathrm{b}^{*}}$ & $1.42^{\mathrm{b}^{*}}$ \\
\hline Diabetic + & $6.92 \pm$ & $12.02 \pm$ & $66.31 \pm$ & $13.92 \pm$ \\
Metformin & $0.44^{\mathrm{b}^{*}}$ & $1.41^{\mathrm{b}^{*}}$ & $4.40^{\mathrm{b}^{*}}$ & $1.38^{\mathrm{b}^{*}}$ \\
\hline
\end{tabular}

Units are expressed as: Plasma LPL- $\mu$ moles of glycerol liberated $/ \mathrm{h} / \mathrm{L}$; Plasma LCAT- $\mu$ moles of cholesterol esterified/h/L; Liver LPL- $\mu$ moles of free fatty acids liberated $/ \mathrm{h} / \mathrm{mg}$ protein; Liver LCAT- $\mu$ moles of cholesterol esterified $/ \mathrm{h} / \mathrm{mg}$ protein

Values are given as Mean \pm S.E.M for six rats in each group. One way ANOVA followed by post hoc test LSD. Statistical significance was compared within the groups as follows:

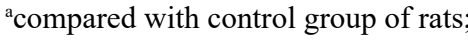

${ }^{b}$ compared with diabetic group of rats.

Values are statistically significant at $* \mathrm{p}<0.05$.

\section{Discussion}

Persistent hyperlipidemia, hypercholesterolemia and hypertriglyceridemia are the terms often used to signify the abnormalities associated with lipid alterations observed during chronic hyperglycemia in type 2 diabetes mellitus. The chronic hyperglycemia in T2DM arises primarily due to the development of insulin resistance in the peripheral tissues[32,33] in association with insufficient secretion of insulin from the $\beta$-cells of pancreas which in turn associated with profound alterations in the plasma lipid and lipoprotein profile and with an increased risk of premature atherosclerosis, coronary insufficiency and myocardial infarction[34]. Several reports evidenced that the fatty acids, which under normal circumstances serve as physiological fuels for the $\beta$-cells, become toxic when available at elevated levels for a prolonged duration of time[35,36].

The major pathogenesis of lipid abnormalities in diabetes includes increased mobilization of fatty acids from adipose tissue and secondary elevation of free fatty acids in the blood, leading to the production of ketone bodies[37]. The liver and other tissues participate in the uptake, oxidation and metabolic conversion of free fatty acids, synthesis of cholesterol as well as phospholipids and secretion of specific classes of plasma lipoproteins.Diabetes is also known to be associated with an increase in the synthesis of cholesterol which may be due to the increased activity of insulin sensitive HMG-CoA reductase[38].

Cholesterol, the decorated small molecule with multiple loop structure derived from its simple acetate precursor, is an important component of cell membranes where it occupies the spaces between the polar head groups of phospholipids and reducing the membrane fluidity[39]. Cholesterol synthesis is a very energetic expensive process involving four stages which require 18 acetyl-Co A, 18 ATP, $16 \mathrm{NADH}$ and $4 \mathrm{O} 2$ molecules. It serves as a precursor for vitamin $\mathrm{D}$, bile salts and steroid hormones[40]. Dietary cholesterol constitutes about $20 \%$ total cholesterol while the remaining $80 \%$ is newly synthesized by de novo synthesis. Altogether $900 \mathrm{mg}$ of cholesterol is synthesized in the liver and central nervous system (CNS)per day and is excreted as bile salts which are liver mediated since mammals are unable to hydrolyze cholesterol[41]. An elevated level of cholesterol is a powerful risk factor for the development of coronary heart diseases and the degree of hypercholesterolemia is directly proportional to the severity of diabetes. It has beenrecommended that the education on the adverse effects of hypercholesterolemia and the ways of managing the alterations in the lipid profileshould be provided to diabetics[42]. An increase in the hepatic cholesterol levels might be due to an increase in the transport of chylomicron cholesterol to the liver[43].

Experimental evidence suggests that the deleterious effects of fatty acids are mediated via lipid-derived intracytosolic metabolites rather than by fatty acid oxidation[44]. Free fatty acids (FFAs) play an important role in the development of insulin resistance. Circulating FFAs are primarily derived from the cleavage of triacylglycerol (TAG) of fat deposits by enzymes, notably fatty triacylglycerol lipase and hormone sensitive lipase[45]. FFAs released from intra-abdominal adipose tissue enter into the circulation and cause insulin resistance. The excess of FFAs in the liver leads to stimulation of gluconeogenesis and hepatic glucose output, which primarily contribute to the development of increased fasting plasma glucose levels and the onset of diabetes[46].

Further, the elevated FFA levels inhibit the translocation of glucose transporter GLUT4 in the skeletal muscle which is the major site of total glucose utilization in the body[47]. The inhibition of glucose transporter GLUT4 causes a reduction in glucose uptake in muscle resulting in postprandial hyperglycemia. Similar to the liver, it leads to the development of intramyocellular fat accumulation and impairment of mitochondrial function. There is an assumption that the increased influx of FFAs into pancreatic $\beta$-cells through lipotoxicity mechanism contributes to the loss of their secretory capacity and definite manifestation of type 2 diabetes[48]. The elevated levels of free fatty acids observed in the plasma, liver and kidney tissues of diabetic rats in the present study may be attributed to the increased transport of fatty acids as a result of their excessive mobilization which in turn promote the synthesis of phospholipids and cholesteryl esters by the liver and kidney. Oral administration of GTF-231 in diabetic rats reduces the level of liver and kidney free fatty acids and thereby alleviates diabetic dyslipidemia. Further, the elevated levels of plasma lipids in diabetics are essentially due to an increase in the mobilization of free fatty acids from the peripheral depots since insulin inhibits the activity of hormone sensitive lipase. Treatment with GTF-231 indiabetic rats resulted in the amelioration of hyperlipidemia and this may be attributed to the enhanced glucose utilization. Alam et al.[49] have reported that 
Citation: Subramanian,S.S., et al. Amelioration of Diabetic Dyslipidemia by GTF - 231 (Gymnemic acid, Trigonelline and Ferulic acid- 2:3:1), a phytochemical preparation Studied in High Fat Diet Fed-Low Dose STZ Induced Experimental Type 2 Diabetes in Rats. (2018) J diab Obes 5(1): 1- 9.

the oral administration of Ziabeetein, a polyherbal formulation comprising of ten phytoingredients significantly ameliorates both hyperglycemia and hyperlipidemia in STZ induced experimental diabetic rats.

Phospholipids constitute the vital part of biomembranes rich in polyunsaturated fatty acids which are susceptible substrates for free radicals. The elevated plasma phospholipid levels are a consequence of elevated lipoproteins. The plasma cholesterol/phospholipids ratio is one of the important markers for the development of atherosclerosis[50]. The restoration of phospholipids level by GTF-231 may be due to the restricted mobilization of plasma triglycerides, regulating the tissue metabolism and improving the level of insulin secretion and action presumably mediate cholesterol and phospholipids.

In humans, cholesterol circulates as a component of plasma lipoproteins such as chylomicrons, VLDL, LDL, IDL and HDL in the range of $150-250 \mathrm{mg} / \mathrm{dl}$. The characteristic features of diabetic dyslipidemia which aggravate the lipid accumulation in the arterial wall and the formation of atherosclerotic plaques are increased triglycerides, small dense LDL-cholesterol and low HDL cholesterol levels[51]. Triglyceride rich lipoproteins such as chylomicrons and VLDL mediate the delivery of TG to the peripheral tissues while LDL transports cholesterol to peripheral tissues. Cholesterol transport via LDL is often referred to as "Bad Cholesterol'"[52]. HDL-c particles are critical acceptors of cholesterol which mediates the transport of cholesterol back to the liver (for excretion or recycling[53]. Thus, a reduced plasma level of HDL-C is a major risk factor for the development of atherosclerosis induced coronary heart disease and peripheral vascular disease. In mammalian species, a major portion of the cholesterol synthesis takes place in peripheral tissues which lack enzymes to degrade cholesterol. The transfer of cholesterol from the peripheral tissues into HDL occurs by simple diffusion or during transient binding to the cell membranes[54]. In the present study, elevated levels of total cholesterol, triglycerides, free fatty acids and phospholipids in the plasma, liver and kidney were observed in diabetic rats. The increased levels of these cholesterol indices are due to the decreased level of HDL-cholesterol. This in turn, results in decreased removal of cholesterol from the extrahepatic tissues by the HDL-cholesterol[55]. The observed increase in the level of HDL-c with a concomitant decrease in the levels of total cholesterol, triglycerides, free fatty acids and phospholipids in the diabetic rats treated with GTF-231 suggested the efficacy of the phytochemicals in ameliorating the abnormalities in the lipid metabolism during chronic hyperglycemia.

Atherogenic dyslipidemia is characterized by increased levels of triacylglycerol (also an increased number of VLDL particles), LDL-c, apolipoprotein B (apoB) particles and low HDL-c[56]. LDL particles are closely associated with metabolic syndrome and are low-density lipoproteins. Small LDL particles are more atherogenic than larger LDL[57] because they can easily pass through the vessel wall, where LDL is more susceptible to atherogenic changes. A higher amount of small LDL particles is associated with increased atherogenic potential[58]. HDL is an antiatherogenic particle, increasing reverse cholesterol transport and has anti-inflammatory propertiesin addition to protection against the modifications of LDL[59]. Low levels of HDL strongly predict the development of atherosclerotic CVD. In the present study, GTF-231controls the atherogenic and coronary risk factor index by increased HDL-c and decreased total cho- lesterol as well as LDL-c levels.

HFD-STZ induced rats showed abnormalities in lipid metabolism as evidenced by increased TG, TC, VLDL-c and LDL-c levels. Hypertriglyceridemia observed in high fat fedlow dose STZ induced diabetic rats may be due to increased absorption and formation of triglycerides in the form of chylomicrons following exogenous consumption of the diet rich in fat or through increased endogenous production of TG-enriched hepatic VLDL and decreased TG uptake in peripheral tissues. Khera and Bhatia have reported that the oral administration of Woodfordia fruticosaflower Extract significantly ameliorates the alterations in the levels of lipoprotein components in high cholesterol diet fed mice[60]. Hypercholesterolemia may be attributed to increased dietary cholesterol absorption from the small intestine following the intake of HFD in a diabetic condition[16,61]. However, oral administration of GTF-231 normalized the status of lipid profile indicating its potential as an antidyslipidemic agent.

Chylomicrons, primarily secreted by the enterocytes are rich in triglycerides which constitute principal fat in the diet[62]. In the blood circulation, chylomicrons come into contact with lipoprotein lipase (LPL) which hydrolyses the triglyceride of chylomicrons remnants such as VLDL and LDL which are removed by the liver by a process which involves binding to heparan sulphate and a multiligand receptor, the LDL receptor-like protein[63]. LCAT is a key enzyme that catalyzes the esterification of free cholesterol in plasma lipoproteins and plays a critical role in HDL metabolism. GTF-231 modulates the lipid metabolizing enzyme by increased activities of LPL and LCAT in both plasma and hepatic tissue.

In recent times, the RCT concept is used to refer steps to specific cell types involved in the process. Cholesterol efflux from macrophage foam cells is referred to as macrophage-specific RCT which is the major target of lipid-modifying therapies. The concept of RCT was proposed 60 years ago[64,65]. Cholesterol can be effluxed from the macrophage-derived foam cells present in the atherosclerotic plaque only in the face or unesterified form, but not as cholesterol ester. Free cholesterol can leave the macrophage by different pathways, which either transporter-dependent or independent. In the dependent pathway, cholesterol transporters such as scavenger receptor class B types (SR-B1), ATP-binding cassette transporter A1 (ABCA1) and ABCG1 play a crucial role in cholesterol removal[66]. Because regulation and metabolism of HDL-c are highly complex and there are several subclasses with different functions in HDL-c, it levels should be used with caution as a surrogate for predicting fluxes through the RCT pathway[67].

CETP is a member of the lipid transfer/ lipopolysaccharide binding protein gene family which promotes the exchange of neutral lipid species between lipoprotein fractions[68]. CETP is a hydrophobic glycoprotein that is primarily secreted by the liver and circulates in plasma, bound mainly to HDL[69]. It promotes the redistribution of CEs, TGs and to a lesser extent PL between plasma lipoproteins. CETP transfers lipids from one lipoproteins particle to another in a process that results in equilibration of lipids between lipoproteins fractions. It was reported to have a major role in the cholesteryl ester and triglyceride content of the lipid core of VLDL, LDL and HDL. Although CETP activity rises in the presence of increasing amounts LDL, it is inhibited in the presence of high amounts of HDL[70]. This 
leads to the hypothesis that some components that are present in HDL may act as CETP inhibitors[71,72]. Furthermore, the surface charge of HDL plays an important role in the regulation of CETP activity[73,74]. CETP is a key factor controlling cholesterol transport and metabolism through the ability to transfer cholesterol esters from the anti-atherogenic HDL towards pro-atherogenic VLDL and LDL. CETP inhibition was associated with significant increase in HDL cholesterol at the expense of LDL cholesterol[75-77]. The observations on the role of RCT and CETP in regulating lipids and lipoproteins abnormalities have led to an interest in the development of novel strategies to prevent atherosclerosis and its thromboembolic complications.

\section{Conclusion}

In conclusion, the results of the present study clearly evidenced the antihyperlipidemic properties of GTF-231 in addition to its antidiabetic properties. Further studies are in progress to understand the molecular mechanisms involved in the amelioration of diabetic dyslipidemia by GTF-231 to throw more light on the efficacy of the GTF. However, the data presented raise the possibility that GTF-231 may be used as a therapeutic supplement for the treatment of diabetes and its secondary complications.

Acknowledgement: The financial assistance provided to the first author by the University Grants Commission (UGC), New Delhi, India is gratefully acknowledged.

Declaration of Interest: The authors declare that they have no conflicts of interest.

\section{References}

1. Taskinen, M.R. Diabetic dyslipidemia. (2002) Atheroscler Suppl 3(1): 47-51.

Pubmed | Crossref | Others

2. Ginsberg, H.N., Zhang, Y.L., Hernandez-Ono, A. Regulation of plasma triglycerides in insulin resistance and diabetes. (2005) Arch Med Res, 36(3): 232-240.

Pubmed |Crossref | Others

3. Cholesterol Treatment Trialists' (CTT) Collaboration., Baigent, C., Blackwell, L., et al.. Efficacy and safety of more intensive lowering of LDL cholesterol: a meta-analysis of data from 170,000 participants in 26 randomised trials. (2010) Lancet 376(9753): 1670-1681.

Pubmed | Crossref| Others

4. Badimon, L., Vilahur, G., LDL-cholesterol versus HDL-cholesterol in the atherosclerotic plaque: inflammatory resolution versus thrombotic chaos. (2012) Ann N Y Acad Sci 1254: 18-32.

Pubmed |Crossref| Others

5. Schade, D.S., Cavanaugh, B., Ramo, B., et al. The Application of the LDL Principle. (2006) World Journal of Cardiovascular Diseases 6(5): 109-125.

Pubmed |Crossref $\mid$ Others

6. Haffner, S.M., Miettinen, H., Stern, M.P. The homeostasis model in the San Antonio Heart Study. (1997) Diabetes Care 20(7): 1087-1092. Pubmed | Crossref| Others

7. Hajar, R., Statins: Past and Present. (2011) Heart Views 12(3): 121127.

Pubmed | Crossref | Others

8. Mahamuni, S.P., Khose, R.D., Menaa, F., et al. Therapeutic approaches to drug targets in hyperlipidemia. (2012) BioMedicine 2(4): 137. Pubmed | Crossref | Others
9. Seto, S.W., Yang, G.Y., Kiat, H., et al. Diabetes Mellitus, Cognitive Impairment, and Traditional Chinese Medicine. (2015) Int J Endocrinol 810439.

Pubmed |Crossref $\mid$ Others

10. Roshana Devi, V., Sriram Prasath, G., Subramanian, S. Antidiabetic properties of GTF - 231, an ayurvedic formulation studied in high fat diet fed-low dose STZ induced experimental type 2 diabetes in rats. (2015) Der Pharmacia Lettre 7 (7): 113-123.

Pubmed |Crossref |Others

11. Tiwari, P., Mishra, BN., Sangwan, N.S. Phytochemical and Pharmacological Properties of Gymnema sylvestre: An Important Medicinal Plant. (2014) Biomed Res Int 830285: 1-18.

Pubmed |Crossref | Others

12. Folwarczna, J., Janas, A., Pytlik, M., et al. Effects of Trigonelline, an Alkaloid Present in Coffee, on Diabetes-Induced Disorders in the Rat Skeletal System. (2016) Nutrients 8(3):133.

Pubmed | Crossref | Others

13. Naowaboot, J., Piyabhan, P., Munkong, N., et al. Ferulic acid improves lipid and glucose homeostasis in high-fat diet-induced obese mice. (2016) Clin Exp Pharmacol Physiol 43(2): 242-250.

Pubmed |Crossref |Others

14. Roshana Devi, V., Subramanian, S.P. Biochemical Evaluation of Hypoglycemic Effect of GTF-231, a Polyherbal Preparation in High Fat Diet Fed- Low Dose STZ Induced Experimental Type 2 Diabetes in Rats. (2016) Der Pharmacia Lettre 8 (18): 121-132.

Pubmed |Crossref $\mid$ Others

15. Reed, M.J., Meszaros, K., Entes, L.J., et al. A new rat model of type 2 diabetes: the fat-fed, streptozotocin-treated rat. (2000) Metabolism 49(11): 1390-1394.

Pubmed | Crossref | Others

16. Srinivasan, K., Viswanad, B., Asrat, L., et al. Combination of highfat diet-fed and low-dose streptozotocin-treated rat: a model for type 2 diabetes and pharmacological screening. (2005) Pharmacol Res. 52(4): 313-320.

Pubmed |Crossref | Others

17. Nayak, S.S., Pattabiraman, T.N. A new colorimetric method for the estimation of glycosylated hemoglobin. (1981) Clin Chim Acta 109(3): 267-274.

Pubmed | Crossref | Others

18. Folch, J., Lees, M., Stanley, G.H. A simple method for the isolation and purification of total lipids from animal tissues. (1957) J Biol Chem 226(1): 497-509.

Pubmed |Crossref | Others

19. Parekh, A.C., Jung, D.H., Cholesterol determination with ferric acetate uranyl acetate and sulphuric acid-ferrous sulphate reagents. (1970) Anal Chem 42(12): 1423-1427.

Pubmed $\mid$ Crossref $\mid$ Others

20. Foster, L.B., Dunn, R.T. Stable reagents for determination of serum triglycerides by a colorimetric Hantzsch condensation method. (1973) Clin Chem 19(3): 338-340.

Pubmed | Crossref $\mid$ Others

21. Itaya, K., A more sensitive and stable calorimetric determination of free fatty acids in plasma. 1977) J Lip Res, 18, 663- 665.

Pubmed | Crossref $\mid$ Others

22. Bartlett, G.R. Phosphorus assay in column chromatography. (1959) J Biol Chem, 234(3): 466-468.

Pubmed | Crossref | Others

23. Fiske, C.H., SubbaRow, Y. The Colorimetric Determination of Phosphorus. (1925) J Biol Chem 66: 375-400.

Pubmed |Crossref $\mid$ Others

24. Burstein, M., Scholnick, H.R. Precipitation of chylomicron and very low density protein from human serum with sodium lauryl sulphate. (1972) Life Sci 11(4): 177-184.

Pubmed | Crossref $\mid$ Others

25. Friedewald, W.T., Levy, R.I., Fredrickson, D.S. Estimation of the concentration of low-density lipoprotein cholesterol in plasma, without 
Citation: Subramanian,S.S., et al. Amelioration of Diabetic Dyslipidemia by GTF - 231 (Gymnemic acid, Trigonelline and Ferulic acid- 2:3:1), a phytochemical preparation Studied in High Fat Diet Fed-Low Dose STZ Induced Experimental Type 2 Diabetes in Rats. (2018) J diab Obes 5(1): 1- 9.

use of the preparative ultracentrifuge. (1972) Clin Chem 18(6): 499502.

Pubmed | Crossref $\mid$ Others

26. Abbott, R.D., Wilson, P.W., Kannel, W.B., et al. High density lipoprotein cholesterol, total cholesterol screening, and myocardial infarction. The Framingham Study. (1988) Arteriosclerosis 8(3): 207-211.

Pubmed |Crossref $\mid$ Others

27. Adeneye, A.A., Adeyemi, O.O., Agbaje, E.O., Anti-obesity and antihyperlipidaemic effect of Hunteria umbellata seed extract in experimental hyperlipidaemia. (2010) J Ethnopharmacol 130(2): 307-314. Pubmed | Crossref | Others

28. Rao, A.V., Ramakrishnan, S. Indirect assessment of hydroxymethylglutaryl-CoA reductase (NADPH) activity in liver tissue. (1975) Clin Chem 21(10): 1523-1525.

Pubmed | Crossref | Others

29. Korn, E.D. Clearing factor: a heparin activated lipoprotein lipase: isolation and characterization of enzyme from normal rats. (1955) J Biol Chem215(1): 1-14.

Pubmed | Crossref $\mid$ Others

30. Schmidt, A. Measurement of lipoprotein lipase and hepatic triglyceride lipase in human postheparin plasma. (1974) Methods Enzymol 72: 325-337.

Pubmed | Crossref|Others

31. Hitz, J., Steinmetz, J., Siest, G. Plasma lecithin: cholesterol acyltransferase-reference values and effects of xenobiotics. (1983) Clin

Chim Acta 133(1): 85-96.

Pubmed | Crossref| Others

32. Porte, D., Kahn, S.E. Beta-cell dysfunction and failure in type 2 diabetes: potential mechanisms. (2001) Diabetes 50: S160- S163.

Pubmed |Crossref | Others

33. DeFronzo, R.A., Tripathy, D. Skeletal muscle insulin resistance is the primary defect in type 2 diabetes. (2009) Diabetes Care 32(2): S157- S163.

Pubmed | Crossref | Others

34. Reasner, C.A. Reducing cardiovascular complications of type 2 diabetes by targeting multiple risk factors. (2008) J Cardiovasc Pharmacol 52(2) 136-144.

Pubmed | Crossref | Others

35. Jacqueminet, S., Briaud, I., Rouault, C. Inhibition of insulin gene expression by long-term exposure of pancreatic $\beta$-cells to palmitate is dependent on the presence of a stimulatory glucose concentration. (2000) Metabolism 49(4) $532-536$.

Pubmed | Crossref | Others

36. Briaud, I., Harmon, J.S., Kelpe, C.L. et al. Lipotoxicity of the pancreatic $\beta$-cell is associated with glucose-dependent esterification of fatty acids into neutral lipids. (2001) Diabetes 50(2): $315-321$.

Pubmed | Crossref| Others

37. Guilherme, A., Virbasius, J.V., Puri, V., et al. Adipocyte dysfunctions linking obesity to insulin resistance and type 2 diabetes. (2008) Nat Rev Mol Cell Biol 9(5): 367-377.

Pubmed | Crossref| Others

38. Li, T., Chiang, J.Y.L. Regulation of Bile Acid and Cholesterol Metabolism by PPARs. (2009) PPAR Research (2009): 1-15.

Pubmed | Crossref | Others

39. Brown, M.S., Goldstein, J.L. A receptor-mediated pathway for cholesterol homeostasis. (1986) Science 232(4746): 34-47.

Pubmed | Crossref | Others

40. Zerenturk, E.J., Sharpe, L.J., Brown, A.J. Sterols regulate 3 $\beta$-hydroxysterol $\Delta 24$-reductase (DHCR24) via dual sterol regulatory elements: cooperative induction of key enzymes in lipid synthesis by Sterol Regulatory Element Binding Proteins. (2012) Biochim Biophys Acta 1821(10): 1350-1360.

Pubmed | Crossref| Others

41. Goldstein, J.L., Brown, M.S. Regulation of the mevalonate pathway. (1990) Nature 343(6257): 425-30.

Pubmed | Crossref | Others
42. Mahmoud, A.M., Bhogireddy, N., Bhaskaran, A.A. The Enormity of Total Serum Cholesterol Levels and the Scale of Awareness on Control and Management of Cholesterol in Diabetics in Zanzibar. (2014) Pharm Phytopharmacol Res 3(6): 429-433.

Pubmed |Crossref $\mid$ Others

43. Vergès, B. Pathophysiology of diabetic dyslipidaemia: where are we?. (2015) Diabetologia 58(5): 886-899.

Pubmed | Crossref | Others

44. Poitout, V., Robertson, R.P. Minireview: Secondary beta-cell failure in type 2 diabetes--a convergence of glucotoxicity and lipotoxicity. (2002) Endocrinology 143(2): 339-342.

Pubmed | Crossref| Others

45. Petersen, K.F., Shulman, G.I. Etiology of insulin resistance. (2006) Am J Med 119(5): S10- S16.

Pubmed | Crossref | Others

46. Grundy, S.M., Cleeman, J.I., Daniels, S.R., et al. Diagnosis and management of the metabolic syndrome: an American Heart Association/National Heart, Lung, and Blood Institute Scientific Statement. (2005) Circulation 112(17): 2735-2752.

Pubmed | Crossref| Others

47. Kelley, D.E., Mandarino, L.J. Hyperglycemia normalizes insulin-stimulated skeletal muscle glucose oxidation and storage in noninsulin-dependent diabetes mellitus. (1990) J Clin Invest 86(6): 1999-2007. Pubmed | Crossref | Others

48. Tkac, I., Kimball, B.P., Lewis, G., et al. The severity of coronary atherosclerosis in type 2 diabetes mellitus is related to the number of circulating triglyceride-rich lipoprotein particles. (1997) Arterioscler Thromb Vasc Biol 17(12): 3633-3638.

Pubmed | Crossref | Others

49. Alam, S., Baig, A., Kavya, S., et al. Antidiabetic and Antihyperlipidemic Effects of Aqueous Extract of Polyherbal formulation (Ziabeetein Powder) in Experimental Animals. (2013) Int J Pharm Phytopharmacol Res 2(4): 263-267.

Pubmed | Crossref $\mid$ Others

50. Upadhyay, R.K. Emerging Risk Biomarkers in Cardiovascular Diseases and Disorders. (2015) J Lipids 2015 (971453): 1-50.

Pubmed | Crossref | Others

51. Muacevic-Katanec, D., Reiner, Z. Diabetic dyslipidaemia or 'diabetes lipidus'?. (2011) Expert Rev Cardiovasc Ther 9(3): 341-348.

Pubmed | Crossref| Others

52. Daniels, T.F., Killinger, K.M., Michal, J.J., et al. Lipoproteins, cholesterol homeostasis and cardiac health. (2009) Int J Biol Sci 5(5): 474-488.

Pubmed | Crossref $\mid$ Others

53. Lagrost, L., Gambert, P. HDL and reverse cholesterol transport, Role of cholesterol ester transfer protein. (1992) C R Seances Soc Biol Fil 186(4): 405-413.

Pubmed | Crossref | Others

54. Maxfield, F.R., van Meer, G. Cholesterol, the central lipid of mammalian cells. (2010) Curr Opin Cell Biol 22(4): 422-429.

Pubmed | Crossref| Others

55. Loh, K.C., Tan, M.H. Reverse cholesterol transport: its contribution to cholesterol catabolism in normal and disease states. (1996) Can J Cardiol 12(10): 944-950.

Pubmed | Crossref $\mid$ Others

56. Reaven, G.M., Chen, Y.D., Jeppesen, J., et al. Insulin resistance and hyperinsulinemia in individuals with small, dense low density lipoprotein particles. (1993) J Clin Invest 92(1): 141-146.

Pubmed | Crossref|Others

57. Krauss, R.M. Dietary and Genetic Probes of Atherogenic Dyslipidemia. (2005) Arteriosclerosis, Thrombosis and Vascular Biology 25(11): 2265-2272.

Pubmed | Crossref | Others

58. Blake, G.J., Otvos, J.D., Rifai, N., et al. Low-density lipoprotein particle concentration and size as determined by nuclear magnetic resonance spectroscopy as predictors of cardiovascular disease in women. 
(2002) Circulation 106(15): 1930-1937.

Pubmed |Crossref|Others

59. Nofer, J.R., Kehrel, B., Fobker, M., et al. HDL and arteriosclerosis: beyond reverse cholesterol transport. (2002) Atherosclerosis 161(1): $1-16$.

Pubmed | Crossref | Others

60. Khera, N., Bhatia, A. Antihyperlipedemic Activity of Woodfordia fruticosa Extract in High Cholesterol Diet Fed Mice. (2012) Int J Pharm Phytopharmacol Res 2(3): 211-215.

Pubmed |Crossref| Others

61. Veerapur, V.P., Prabhakar, K.R., Thippeswamy, B.S., et al. Antidiabetic effect of Dodonaea viscose (L) Lacq, aerial parts in high fructose-fed insulin resistant rats: A mechanism based study. (2010) Indian J Exp Biol 48(8): 800-810.

Pubmed |Crossref| Others

62. Demignot, S., Beilstein, F., Morel, E. Triglyceride-rich lipoproteins and cytosolic lipid droplets in enterocytes: key players in intestinal physiology and metabolic disorders. (2014) Biochimie 96: 48-55.

Pubmed|Crossref|Others

63. Krieger, M., Herz, J. Structures and functions of multiligand lipoprotein receptors: macrophage scavenger receptors and LDL receptor-related protein. (1994) Annu Rev Biochem 63: 601-637.

Pubmed | Crossref | Others

64. Glomset, J.A., Wright, J.L. Some properties of a cholesterol esterifying enzyme in human plasma. (1964) Biochim Biophys Acta 89(2): 266-276.

Pubmed | Crossref| Others

65. Glomset, J.A. The plasma lecithins:cholesterol acyltransferase reaction. (1968) J Lipid Res 9(2): 155-167.

Pubmed |Crossref| Others

66. Wang, M.D., Franklin, V., Marcel, Y.L. In vivo reverse cholesterol transport from macrophages lacking ABCA1 expression is impaired. (2007) Arterioscler Thromb Vasc Biol 27(8): 1837-1842.

Pubmed | Crossref | Others

67. Ono, K. Current concept of reverse cholesterol transport and novel strategy for atheroprotection. (2012) J Cardiol 60(5): 339-343.

Pubmed | Crossref | Others

68. Day, J.R., Albers, J.J., Lofton-Day, C.E., et al. Complete cDNA encoding human phospholipid transfer protein from human endothelial cells. (1994) J Biol Chem 269(12): 9388-9391.

Pubmed |Crossref|Others

69. Tall, A.R. Plasma lipid transfer proteins. (1995) Annu Rev Biochem

64: 235-257.

Pubmed | Crossref | Others

70. Cazita, P.M., Barbeiro, D.F., Moretti, A.I., et al. Human cholesteryl ester transfer protein expression enhances the mouse survival rate in an experimental systemic inflammation model: a novel role for CETP. (2008) Shock 30(5): 590-595.

Pubmed|Crossref| Others

71. Son, Y.S., Zilversmit, D.B. Purification and characterization of human plasma proteins that inhibit lipid transfer activities. (1984) Biochim Biophys Acta 795(3): 473-480.

Pubmed|Crossref|Others

72. Lagrost, L. Regulation of cholesteryl ester transfer protein (CETP) activity: review of in vitro and in vivo studies. (1994) Biochim Biophys Acta 1215(3): 209-236.

Pubmed | Crossref | Others

73. Masson, D., Athias, A., Lagrost, L. Evidence for electronegativity of plasma high density lipoprotein-3 as one major determinant of human cholesteryl ester transfer protein activity. (1996) J Lipid Res 37(7): 1579-1590.

Pubmed | Crossref | Others

74. Dumont, L., Gautier, T., de Barros, J.P., et al. Molecular mechanism of the blockade of plasma cholesteryl ester transfer protein by its physiological inhibitor apolipoprotein CI. (2005) J Biol Chem 280(45): 38108-38116.

Pubmed |Crossref | Others
75. Okamoto, H., Yonemori, F., Wakitani K., et al. A cholesteryl ester transfer protein inhibitor attenuates atherosclerosis in rabbits. (2000) Nature 406(6792): 203-207.

Pubmed |Crossref|Others

76. Brousseau, M.E., Schaefer, E.J., Wolfe, M.L., et al. Effects of an inhibitor of cholesteryl ester transfer protein on HDL cholesterol. (2004) N Engl J Med 350(15): 1505-1515.

Pubmed | Crossref| Others

77. Clark, R.W., Sutfin, T.A., Ruggeri, R.B., et al. Raising high-density lipoprotein in humans through inhibition of cholesteryl ester transfer protein: an initial multidose study of torcetrapib. (2004) Arterioscler Thromb Vasc Biol 24(3): 490-497.

Pubmed | Crossref | Others 